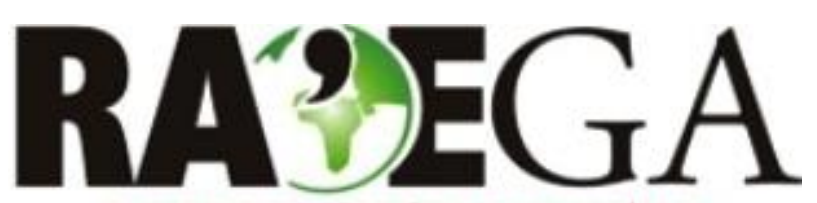

O ESPAÇO GEOGRÁFICO EM ANÁLISE

\title{
TÉCNICAS AGRÍCOLAS, PRESERVAÇÃO E IMPACTOS AMBIENTAIS NA REGIÃO OESTE DO PARANÁ
}

\section{TECHNICAL AGRICULTURAL, PRESERVATION AND ENVIRONMENTAL IMPACTS IN THE REGION OF PARANÁ WEST}

\author{
Janice Costa da Silva Fauro \\ Programa de Pós Graduação em Geografia \\ Universidade Estadual de Maringá - UEM \\ Maringá, PR, Brasil \\ e-mail: janice smi@hotmail.com \\ Fernanda Perdigão da Fonseca Toniol \\ Programa de Pós Graduação em Geografia \\ Universidade Estadual de Maringá - UEM \\ Maringá, PR, Brasil \\ e-mail: ferperdigao@hotmail.com \\ Elpídio Serra \\ Docente do Programa de Pós Graduação em Geografia \\ Universidade Estadual de Maringá - UEM \\ Maringá, PR, Brasil \\ e-mail: serraelpidio@gmail.com
}

\section{Resumo}

O objetivo deste artigo é analisar as implicações das transformações tecnológicas da agricultura paranaense e os impactos ambientais decorrentes dessas mudanças estruturais, elegendo como cenário a região Oeste do Paraná. O modelo agrário tecnológico introduzido na agricultura brasileira desde a década de 1950, e, posteriormente (década de 1970), no quadro agrícola paranaense, tem como uma de suas características centrais a exclusão dos pequenos produtores, estimulando a produção de cultivos de elevada cotação comercial (commodities), os quais, por sua natureza, requerem extensas áreas de plantio, em detrimento dos alimentos produzidos pela maioria dos produtores. Cabe destacar que a pressão do setor industrial 
sobre o setor agrícola, fortalecido após o processo de industrialização e de internacionalização do capital, é significativa. A metodologia empregada envolveu a revisão bibliográfica, relacionando os ciclos econômicos que marcaram a ocupação do território paranaense e a exploração dos recursos naturais, como também a manutenção das áreas de preservação ambiental, mais especificamente o Parque Nacional do Iguaçu, instituído em 1939, como reserva de Proteção Integral. A análise dos resultados permitiu considerar o caráter de dispersão das mudanças tecnológicas na agricultura do estado do Paraná, entendendo que nem todas as regiões se tecnificaram e mecanizaram ao mesmo tempo.

Palavras-chaves: Agricultura modernizada; Transformações tecnológicas; Impactos ambientais.

\begin{abstract}
The aim of this paper is to analyze the implications of technological change of Paraná agriculture and environmental impacts of these structural changes, choosing the backdrop of the western Paraná. The technological agricultural model introduced in Brazilian agriculture since the 1950, and (later 1970) in Paraná agricultural framework, has as one of its central features the exclusion of small producers, stimulating the production of high commercial price crops (commodities), which, by their nature, require extensive planting areas at the expense of food produced by most producers. It is noteworthy that the pressure of the industrial sector on the agricultural sector, strengthened after the process of industrialization and internationalization of capital, is significant. The methodology involved a literature review, listing the economic cycles that marked the occupation of the State of Paraná and the exploitation of natural resources, as well as the maintenance of environmental preservation areas, specifically the Iguaçu National Park, established in 1939 as a reserve Full Protection. The results allowed us to consider the character of dispersion of technological change in the state of Paraná agriculture, understanding that not all of its regions make technical and mechanized the same time.
\end{abstract}

Keywords: Agriculture modernized; Technological changes; Environmental impacts.

\title{
1. INTRODUÇÃO
}

O desenvolvimento das inovações tecnológicas na agricultura inserido no contexto mais amplo da chamada modernização agrícola afetou a sociedade como um todo, considerando que as mudanças das práticas 
TÉCNICAS AGRíCOLAS, PRESERVAÇÃO E IMPACTOS AMBIENTAIS NA REGIÃO OESTE DO PARANÁ

tradicionais para uma nova base técnica com atividades cada vez mais modernas se desdobram em consequências que acarretaram mudanças não apenas para o espaço agrário, mas ainda para outros setores, no caso as socioambientais, diretamente relacionadas às populações urbanas e rurais.

As mudanças nas técnicas de produção instauradas desde a base do sistema agrícola com a entrada de insumos químicos, sementes selecionadas, técnicas de plantio até a outra ponta do sistema, onde alcança o espaço urbano industrial com o produto já industrializado, de fato proporcionaram maior produtividade do solo e, sobretudo maiores rendimentos, sob pressão dos mercados urbanos.

Para dar sustentação a essas mudanças, o Estado induziu ações de políticas de apoio governamental (políticas de incentivo de crédito, subsídios, fiscal, tributária, assistência técnica oficial e outras), utilizadas tanto para estimular o cultivo de produtos de maior cotação comercial - commodities (soja, milho e trigo) como para a aquisição dos pacotes tecnológicos (maquinários, insumos, sementes, etc.) necessários para a produção das culturas modernas.

A partir da intrínseca relação, cada vez mais intensa, entre agricultura e (agro) indústria instaurada por este novo modelo agrícola e do acelerado processo de expansão industrial nas décadas de 1950 a 1970 no Brasil, aumenta a preocupação com os danos causados ao meio ambiente, o que leva o governo a retomar o emprego de ações direcionadas à ampliação da política ambiental no país. Contudo, tal estratégia destinada a alavancar a política ambiental, surge em uma posição de subordinação a serviço das necessidades do desenvolvimento econômico capitalista, fato central e preponderante das políticas públicas (VEROCAI, 1991).

$\mathrm{Na}$ sua estrutura e nas suas estratégias a política ambiental abarca o conceito de gestão, utilizado para incluir, além da gestão pública do meio ambiente, ações desenvolvidas por empresas e instituições nãogovernamentais, para administrar suas atividades dentro do princípio de proteção do bem ambiental, responsabilidade essa não apenas do governo, mas sim de toda sociedade. 
No Oeste paranaense a modernização da agricultura a partir da década de 1970, foi acompanhada por problemas ambientais afetando tanto o solo, como a água e o ar, à revelia das políticas ambientais. Discutir as novas formas de produzir na agricultura e os danos ocasionados ao meio ambiente, tendo como espaço de referência essa região do Paraná, considerada uma das mais dinâmicas do País em termos de incorporação de inovações tecnológicas no setor agrícola, é o que se pretende discutir no desenvolvimento do presente trabalho. No que se refere aos problemas ambientais, serão considerados os danos provocados no Parque Nacional do Iguaçu pelas chamadas agriculturas modernas praticadas no entorno da área de preservação.

\section{MATERIAL E MÉTODOS}

A metodologia da pesquisa utilizada levou em conta que um trabalho deve ser entendido como resultado de um conjunto detalhado e sequencial de procedimentos executados, de tal modo que se consiga atingir os objetivos inicialmente propostos (BARRETO; HONORATO, 1998).

Assim, visando estabelecer uma sequência sistemática de procedimentos para a consecução do objetivo proposto, a pesquisa é sustentada por uma revisão bibliográfica, envolvendo as transformações tecnológicas introduzidas na agricultura e as políticas ambientais no Brasil, em particular no Estado do Paraná, com ênfase na região Oeste, onde o parque Nacional do Iguaçu se insere onde foram realizados trabalhos de campo.

A revisão bibliográfica priorizou autores que discutem as relações entre a questão agrária no Brasil e na região Oeste do Paraná, bem como a importância das novas tecnologias e enfatizando os danos ambientais por elas provocados.

Os trabalhos de campo corresponderam a entrevistas aos agricultores, que possuem propriedade no entorno do Parque Nacional do Iguaçu, de fato aqueles com terras em contato direto com a reserva ambiental. 
TÉCNICAS AGRíCOLAS, PRESERVAÇÃO E IMPACTOS AMBIENTAIS NA REGIÃO OESTE DO PARANÁ

\section{RESULTADOS E DISCUSSÃO}

Embora sejam inúmeros os exemplos que poderiam ser citados sobre a relação entre a modernização agrícola e os problemas ambientais gerados, optou-se no presente trabalho por discutir o caso da região Oeste paranaense, visto sua relevante participação no cenário agrícola nacional. Assim, a discussão aqui realizada está sustentada pelo entrelaçamento das vertentes do modelo de colonização regional do Oeste, a nova base técnica da agricultura, dita moderna, e a problemática ambiental.

\section{O PROCESSO DE COLONIZAÇÃO NO OESTE DO PARANÁ}

Com uma colonização marcada pela exploração extrativista de madeira e, na sequência, pela agricultura e pecuária, o Oeste do Paraná se integra à dinâmica da economia nacional somente a partir de 1950, com o assentamento de imigrantes, a produção de excedentes comercializáveis e a implantação de modais de transporte, integrando a região às demais porções do território paranaense e ao restante do Brasil (PIFFER, 2009).

Dentre as principais empresas colonizadoras que atuaram na região destacam-se a Madereira Colonizadora Rio Paraná (MARIPÁ); a Pinho e Terras, com as seções Piquiri, Céu Azul, Porto Mendes e Lopeí; a Industrial Agrícola Bento Gonçalves; a Colonizadora Matelândia e a Colonizadora Criciúma. Essas companhias tinham como objetivo a exploração da madeira, a mercantilização de terras, o comércio e a indústria (GREGORY, 2002).

Nesse período o governo cede espaço para os empreendimentos empresariais, visando à venda de lotes agrícolas aos colonos interessados no cultivo direto da terra. As diversas atividades produtivas e seus desdobramentos em infraestruturas territoriais e deslocamentos populacionais, são fundamentais para compreender o processo de desenvolvimento desigual e combinado que marcou a formação do território paranaense.

No Estado do Paraná, particularmente, de acordo com Padis (1981, p. 15) "a ocupação precária, o desmatamento intenso, a colonização oficial e 
TÉCNICAS AGRíCOLAS, PRESERVAÇÃO E IMPACTOS AMBIENTAIS NA REGIÃO OESTE DO PARANÁ

privada, ou seja, todos os meios foram utilizados para se povoar o território paranaense". A ocupação das cidades, uma rede integrada e bem conservada de estradas, o desenvolvimento da atividade comercial e de serviços e a instalação de pólos agroindustriais foram o coroamento do processo de ocupação do Estado, com base na expansão das atividades agrícolas. Tal processo de ocupação ocorreu diferentemente em três zonas distintas como destacadas pelo IPARDES (2015, p.1): “1) a região denominada de Paraná Antigo, compreendendo áreas localizadas a leste e centro-sul do Estado, a de mais antiga ocupação (período de 1549), marcada por ciclos de exploração agropecuária; 2) a grande região Norte, de penetração/expansão do café paulista (1862); e 3) a Região do Extremo Oeste/Sudoeste, de colonização recente (1939), onde o setor privado dirigiu a ocupação nas terras devolutas, em parceria com o Estado".

Importante observar que a colonização empreendida no Oeste do Paraná pelas companhias colonizadoras e diretamente pelo Estado, baseou-se na pequena propriedade e na atividade agrícola para a subsistência de seus próprios moradores. Com este modo de repartição e ocupação da terra foram garantidas as condições para a fixação do homem no campo e para a manutenção de uma população apegada ao trabalho agrícola, que vai garantir a ocupação desse território fronteiriço, essencialmente deslocada de Santa Catarina e do Rio Grande do Sul (RICARDO, 1970).

Com a vinda dos imigrantes sulistas e o esgotamento das terras destinadas à colonização, na década de 1960 a região Oeste encerra esse ciclo de ocupação e entra numa nova fase econômica. Assim, na década de 1970, o Oeste sofre uma reorganização de sua base produtiva, ocasionada pela modernização da base técnica de produção agropecuária, pela expansão agropecuária regional e o esgotamento da fronteira agrícola. Essas mudanças propiciaram uso intensivo das novas áreas e a reestruturação das tradicionais. Contudo, paralelamente, geraram o desemprego nas lavouras, caracterizadas como muito mais dependentes do fator capital e pouco dependentes do fator 
TÉCNICAS AGRÍCOLAS, PRESERVAÇÃO E IMPACTOS AMBIENTAIS NA REGIÃO OESTE DO PARANÁ

trabalho. O resultado foi um forte êxodo rural para os grandes centros urbanos e, principalmente, para outros Estados brasileiros (PIFFER, 2009).

\subsection{A Evolução das Técnicas Agrícolas na Região Oeste do Paraná}

A mesorregião Oeste do Paraná (Figura 1), situada no Terceiro Planalto Paranaense, é formada por cinquenta municípios e abrange uma área de 2.290.859 hectares (correspondente a 11,5\% do território estadual), segundo Ipardes (2006). Faz fronteira com o Paraguai e a Argentina, e tem como principais divisas os rios Piquiri, Paraná e Iguaçu.

Figura 1 - Localização da Área de Estudo - Mesorregião Oeste-Paranaense

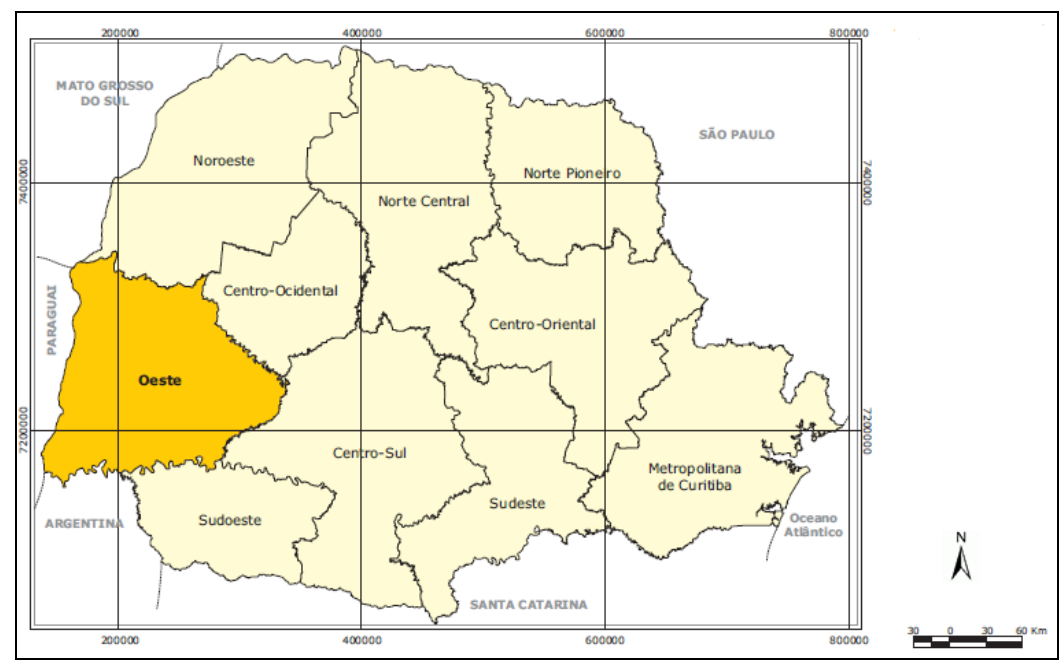

Fonte: Adaptado de IPARDES, 2006

Na primeira metade do século XX inicia-se a última fase da colonização da região, período em que se configura como efetivo povoamento da mesorregião Oeste Paranaense, que ocorreu a partir da campanha denominada Marcha para o Oeste (ANANIAS, 2014). Tratava-se de um programa promulgado pelo presidente da República, Getúlio Vargas, que tinha como objetivo ocupar a fronteira Oeste do Brasil. As terras de fronteira, habitadas por índios, paraguaios e argentinos, deveriam ser ocupadas por pequenos agricultores gaúchos e catarinenses, que se exprimiam, na época, em minifúndios nos seus estados de origem (DEITOS, 2004).

R. Ra'e Ga - Curitiba, v. 36, p. $302-321$, Abr/2016 
Num primeiro momento, a região, comportou uma agricultura realizada a partir de práticas tradicionais, bem como o extrativismo vegetal baseado na extração da erva-mate e da madeira, atividades que se mantiveram até a década de 1960. Em um segundo momento ocorreu à substituição da agricultura tradicional por uma nova base técnica, o novo modelo agrícola, que trouxe como resultado a ampliação do desenvolvimento econômico, a partir da introdução de inovações como mecanização, uso de insumos químicos e de sementes selecionadas, segundo os interesses do mercado agrícola global.

A modernização agrícola se dava assim, como uma implícita exigência do grande capital financeiro e industrial, interessado na disseminação da cadeia interdependente entre culturas modernas e aparato tecnológico.

Encerrava-se, assim, o ciclo da ocupação pioneira e entrava-se numa nova fase econômica: a reestruturação da base produtiva. Essa reestruturação, que marcará principalmente as décadas seguintes, de 1970 e 1980, foi estimulada por proporcionar o aumento da produtividade agropecuária, e também as grandes obras de infraestrutura, como usinas hidroelétricas e estradas (PIFFER, 2009).

Apesar de a mesorregião possuir cinquenta municípios, a polarização se reflete na concentração expressiva do PIB regional em três municípios pólos: Toledo, Cascavel e Foz do Iguaçu. Os municípios de Toledo e Cascavel, com suas economias dinamizadas pelas atividades de transformação e 0 fortalecimento do setor terciário, polarizavam cada vez mais os municípios do seu entorno. Contudo, os municípios da microrregião mantêm um avanço nas atividades de transformação de forma gradual e continuada ao longo do tempo. Diferentemente do município de Foz do Iguaçu que mantém sua economia urbana dinâmica fortalecida no comércio inter-regional, na produção de energia e no turismo (LIMA, 2005).

A realidade da região Oeste modificou-se tanto nas últimas três décadas do século $X X$ que se formaram três territorialidades econômicas no seu espaço, como demonstra a Figura 02, possuindo, na quase totalidade dos municípios, uma economia agrícola expressiva. 
Figura 02 - O Perfil do Quociente de Localização do Setor Primário nos Municípios do Oeste do Paraná - 1970-

2009

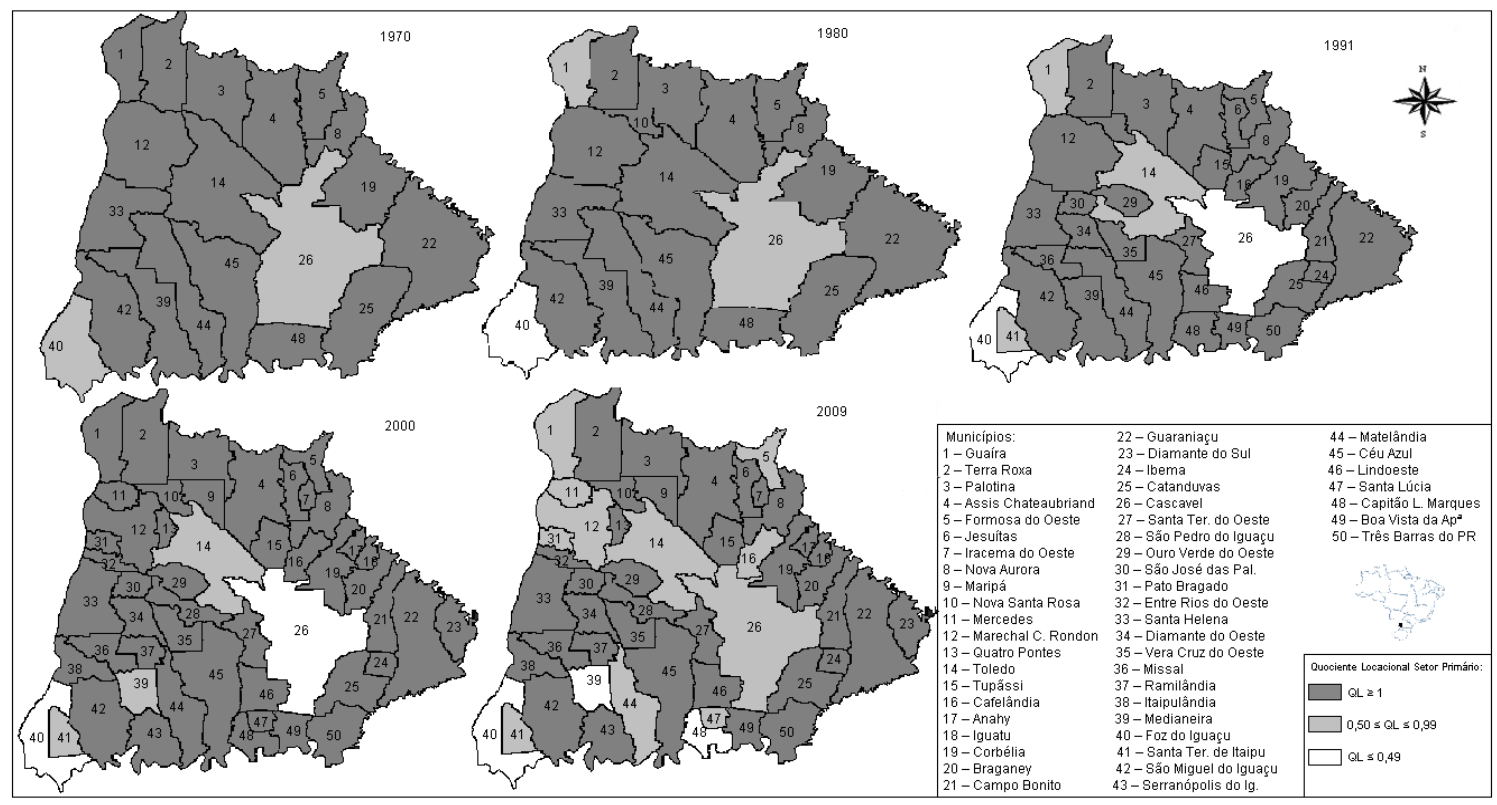

Fonte: FERRERA DE LIMA et al., 2005.

O resultado foi o fortalecimento da economia agrícola, tendo como consequência social uma urbanização alimentada pelo êxodo rural. Na década 
de 1970, quando ocorre o grande avanço de mecanização e as inovações químicas no Estado do Paraná, igualmente na região Oeste, ocorre o mesmo processo de transformações, alavancado por produtores mercantis que, via credito, adquiriram máquinas, visto que não houve uma atividade econômica anterior que possibilitasse uma acumulação previa. Nesse mesmo período ocorre uma redução do trabalho familiar e um aumento do assalariamento nas relações de trabalho.

O crescimento econômico da região torna-se expressivo no início do atual século XXI. Conforme dados do Instituto de Pesquisa Econômica Aplicada - IPEADATA (2010), o Produto Interno Bruto (PIB) regional cresceu $32 \%$ entre 1998 e 2008, perfazendo uma média anual acima de 3\%. Esse crescimento foi estimulado pelas atividades de transformação, baseadas principalmente na agroindústria e na produtividade das propriedades rurais (até 50 hectares), que produzem soja, milho, trigo e a pecuária (aves, porcos e gado leiteiro). Esse crescimento do PIB contrastou com dois fenômenos espaciais na região: a polarização e o perfil do continuum urbano.

A análise do Oeste do Paraná fornece um cenário interpretativo bastante interessante sob o ponto de vista de compreensão das várias formas pelas quais a migração se entrelaça com fatores econômicos e acelera ou retarda um processo de desenvolvimento regional (CUNHA (2004). Para tanto, recorre-se a dados estatísticos relativos à abrangência e ao volume de produção de diferentes culturas, força de trabalho ocupada e dinâmica da estrutura fundiária, buscando elucidar os contornos territoriais daí advindos, bem como 0 papel do Estado, das cooperativas e das empresas nesse processo.

Por outro lado, o desenvolvimento rural é composto por algumas dimensões dentre as quais estão: a ambiental, a econômica e a social. É caracterizado, portanto, como um conceito complexo e multisetorial que revela as desigualdades locais, regionais e territoriais que se estabeleceram no ambiente rural ao longo do tempo (MELO; PARRÉ, 2007). No caso do Oeste, o agronegócio, até a década de 1960, utilizava-se de técnicas rudimentares, mas, a partir desse período, começou a introduzir ideias e práticas que foram 
disseminadas a partir da Revolução Industrial. Dentre essas práticas estão a introdução de sementes de alta produtividade, o uso intenso de insumos químicos, fatores alimentadores da modernização agrícola (TEIXEIRA, 2005).

A consolidação da modernização agrícola no Brasil ocorreu na década de 1970 devido à implementação de uma política de desenvolvimento agrícola durante o regime militar e caracterizou-se pelo surgimento de complexos agroindustriais e de uma política de crédito e financiamento ofertada pelo governo direcionada especialmente ao setor agrícola.

Os principais fatores responsáveis pela transformação da base técnica agrícola foram: maior utilização de equipamentos tecnológicos em relação à mão de obra, aumento das despesas totais e de compostos químicos, aumento da utilização de equipamentos tecnológicos em relação ao uso da terra explorada, aumentos do valor dos investimentos em instalações na atividade agrícola, dos investimentos tecnológicos em transporte e logística, das despesas com agrotóxicos, dos gastos com implementos agrícolas em relação ao uso da terra explorada e dos financiamentos na atividade agrícola (TEIXEIRA, 2005).

As alterações na estrutura agrícola da região Oeste promoveram o esvaziamento demográfico rural e a expansão da rede urbana. $O$ crescimento da atividade agrícola, que se ampliou rapidamente e proporcionou renda e expansão dinâmica do comércio, foi acompanhado, nas décadas de 1980 e 1990, pelo surgimento e crescimento das cidades e das agroindústrias cooperativas. Até esse período, o Oeste do Paraná caracterizava-se como essencialmente agrícola. A partir de então, a indústria local passou a se consolidar e ter sua dinâmica orientada pelo comportamento da transformação agroalimentar (RIPEL, 2005).

Entre as atividades econômicas desenvolvidas no território paranaense, a agricultura foi e ainda é considerada como importante uma vez que definiu as estruturas sociais, econômicas e políticas nos períodos recentes. A disposição territorial em que se desenvolveu essa atividade foi a maior responsável pelo 
modelo de desenvolvimento desigual e combinado que marcou, em outra dimensão, a construção do território brasileiro.

(...) É esse tipo de organização em que se constitui a lavoura brasileira que derivou toda a estrutura do país: a disposição das classes e categorias de sua população, o estatuto particular de cada uma e dos indivíduos que as compõem. $O$ que quer dizer, o conjunto das relações sociais no que têm de mais profundo e essencial (PRADO JR., 2008. p.141).

O acentuado grau de concentração da propriedade fundiária que caracteriza a generalidade da estrutura agrária brasileira é reflexo da natureza de nossa economia e resulta da formação do País desde os primórdios de sua colonização (VINHAS, 1992).

\subsection{As atividades agrícolas próximas às áreas de preservação ambiental}

Em tal contexto, as Unidades de Conservação surgiram como estratégia de ordenamento territorial face à perda da biodiversidade, ocorridas na escala planetária. O não conservacionismo da natureza provocou e ainda provoca a degradação das matas, dos solos e das águas. Para minimizar esses impactos e assegurar a proteção e a manutenção da biodiversidade e dos ambientes naturais remanescentes, ocorre a implantação de uma rede ou sistema de áreas naturais protegidas (SNUC, Lei 9.985/2000).

As inovações, diretamente vinculadas à denominada "Revolução Verde"1, ocasionaram a intensa mecanização que, paralelamente aos fatores positivos, acabaram por ter efeito negativo, no caso, a expulsão de milhares de famílias do campo, a proletarização do trabalhador rural, o aumento populacional periférico do espaço urbano, a concentração fundiária e os

\footnotetext{
1 "Revolução Verde foi um programa que tinha como objetivo explícito contribuir para o aumento da produção e da produtividade agrícola no mundo, através do desenvolvimento de experiências no campo da genética vegetal para a criação e multiplicação de sementes adequadas às condições dos diferentes solos e climas e resistentes às doenças e pragas, bem como da descoberta e aplicação de técnicas agrícolas ou tratos culturais mais modernos e eficientes" (Brum, 1987, p.44).
}

R. Ra'e Ga - Curitiba, v. 36, p. 302 - 321 , Abr/2016 
impactos ambientais. Essas consequências podem ser consideradas tanto como resultado de um conflito materializado, ou seja, pela diversificação econômica de determinada população ocupando e alterando determinado espaço, como de um conflito com conotação ideológica, de expansão necessária, abrangendo aspectos naturais, sociais, culturais e econômicos.

No Estado do Paraná, o Parque Nacional do Iguaçu é uma dessas áreas de proteção integral, considerada de tamanho significativo, e que sobreviveu à ocupação da região quando da abertura de fronteiras agropecuárias e de exploração de madeira, atividades que transformaram o Paraná, com diferentes tipos de usos de suas terras.

O Parque Nacional do Iguaçu foi estabelecido no Brasil no ano 1939 e possui continuação de seu bioma em território argentino. Atualmente, é considerado o último grande remanescente florestal protegido, mas mesmo assim ocorre no seu interior intensa extração de palmito, a caça e outras ilegalidades. Esse aspecto pode ser percebido através do Regulamento dos Parques Nacionais Brasileiros (1979), no qual os planos de manejo são entendidos como um meio, onde a utilização de "técnicas de planejamento ecológico, determine o zoneamento de um Parque Nacional, caracterizando cada uma de suas zonas e propondo seu desenvolvimento físico, de acordo com suas finalidades" (BRITO 2003, p. 61). O plano de manejo do Parque Nacional do Iguaçu estabelece a sua zona de transição ou amortecimento como minimizador dos impactos externos, conforme determina a resolução 13/90 do Conselho Nacional do Meio Ambiente, e também regulamenta quais atividades agropecuárias são permitidas próximo a reserva ambiental.

Contudo, pode-se observar que os principais problemas ambientais no que diz respeito à integridade dos sistemas vitais essenciais ao Parque Nacional do Iguaçu são: a existência de agricultura intensiva na divisa do Parque; rios com alto grau de turbidez pelo carregamento de sedimentos; rios com provável contaminação por agrotóxicos; matas ciliares inexistentes ou insuficientes; áreas degradadas ou com exígua cobertura florestal nas 
TÉCNICAS AGRíCOLAS, PRESERVAÇÃO E IMPACTOS AMBIENTAIS NA REGIÃO OESTE DO PARANÁ

propriedades adjacentes ao Parque; caça e pesca ilegal; e extração ilegal de palmito (DIAS, 2006).

Também legalmente os agricultores devem manter em suas propriedades a Reserva Legal, área de vegetação nativa. No Estado do Paraná esta área deve ocupar pelo menos $20 \%$ da extensão do estabelecimento rural (Código Florestal Brasileiro - Lei Federal n 4771/65), área considerada necessária para conservar e reabilitar processos ecológicos e a biodiversidade, bem como para servir de abrigo e proteção a plantas e animais. O programa criado através do Decreto Estadual 387/99220 é o SISLEG, que atua sob a supervisão do Instituto Ambiental do Paraná (IAP), e estabelece um Sistema Estadual de Implantação de Áreas de Preservação Permanente (APP) e de Reserva Legal (RL) previstas no Código Florestal. O SISLEG possui três metas determinantes para as suas atuações, são elas: a manutenção dos remanescentes florestais nativos; a ampliação da cobertura florestal mínima (com o objetivo de conservar a Biodiversidade e o uso dos recursos florestais), e o estabelecimento das zonas prioritárias para a conservação e recuperação de áreas florestais por meio da formação dos Corredores de Biodiversidade.

O Paraná é um dos estados que lideram a produção de grãos e de outros produtos agropecuários no País, o que, em outras palavras, significa dizer que o custo ambiental é alto. Esta realidade indica a necessidade de ações para se adequar a esse novo paradigma de desenvolvimento. Cabe destacar que as expansões das atividades produtivas avançaram sobre um dos mais importantes biomas do mundo, a Mata Atlântica, considerado pelo Programa das Nações Unidas para o Meio Ambiente (PNUMA) Patrimônio da Humanidade. Todavia, o sucesso das políticas de conservação da biodiversidade depende muito mais da ação coletiva nos subsistemas social e político dos atores em confronto, do que das características culturais dos usuários diretos e indiretos dos recursos a serem preservados (COSTA, 2012).

Quanto mais estiver ocupado por atividades agrícolas o entorno de uma Unidade de Conservação da Natureza, maior será a disparidade entre o índice de extinção e o índice de substituição de espécies. "Cabe destacar também o 
fato de algumas Unidades de Conservação estarem nas proximidades de centros urbanos, o que não é diferente quanto aos prováveis impactos negativos" (WEINER, 1992, p. 199). A propósito, este é o caso do Parque Nacional do Iguaçu, no Oeste do Paraná.

O conjunto dos acontecimentos desencadeados com a modernização agrícola revela que a recuperação da mata ciliar, a descontaminação dos rios, redução do uso de veneno e outros, requerem a construção de uma consciência pautada em bases compromissadas com o meio ambiente e não apenas por discursos envolvendo interesses de agricultores e gestores ambientais.

Os dados do trabalho de campo confirmam que dentre os principais problemas ambientais no que diz respeito à integridade dos sistemas vitais essenciais ao Parque Nacional do Iguaçu são: a existência de agricultura intensiva na divisa do Parque; rios com alto grau de turbidez pelo carregamento de sedimentos; rios com provável contaminação por agrotóxicos; matas ciliares inexistentes ou insuficientes; áreas degradadas ou com exígua cobertura florestal nas propriedades adjacentes ao Parque; caça e pesca ilegal; extração ilegal de palmito juçara e impasse da "Estrada do Colono" (estrada que cortava - Parque ao meio e fazia a ligação entre o município de Capanema e Serranópolis do Iguaçu $)^{2}$.

\footnotetext{
${ }^{2}$ Sobre o efeito dos conflitos envolvendo a "Estrada do colono" consultar tese de DIAS, 2006. R. Ra'e Ga - Curitiba, v. 36, p. 302 - 321 , Abr/2016
} 


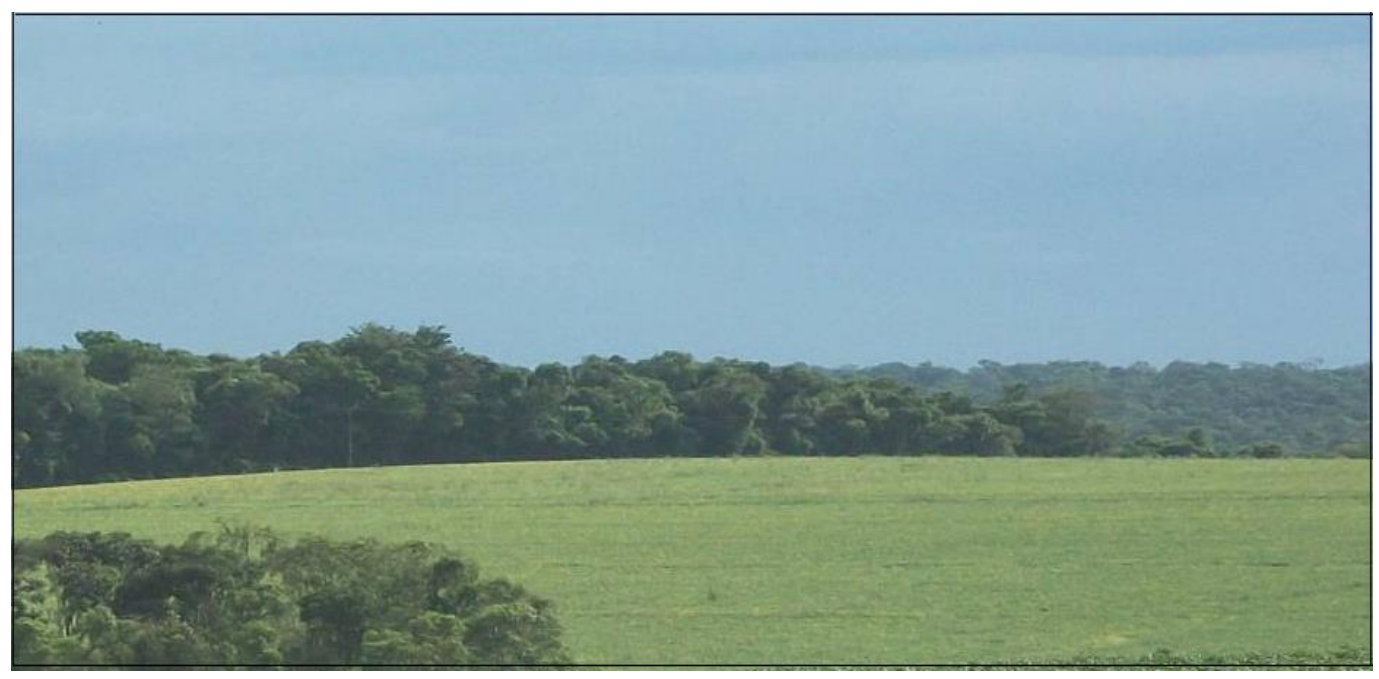

Figura 6- Atividade agrícola realizada na zona de amortecimento do PNI, em São Miguel do Iguaçu-PR. Autor: 2015

A sociedade tem uma significativa importância no equilíbrio do sistema ambiental, pois a partir de sua atuação, sejam de forma direta ou indireta, e a depender de sua intensidade com os demais fatores, pode levar ao desequilíbrio ambiental. Este desequilíbrio é resultante de atividades que ultrapassam as condições limítrofes de sustentabilidade porque ocasionam a degradação ambiental.

O Parque Nacional do Iguaçu representa um remanescente importante, sobressaindo-se como uma ilha em meio a campos de agricultura, principalmente a cultura da soja, como oleaginosa de maior importância na região e em grande parte do Estado do Paraná.

\section{CONSIDERAÇÕES FINAIS}

Ao compreender que as inovações tecnológicas na agricultura trazem benefícios econômicos, mas, em contrapartida, acarretam consequências negativas aos recursos naturais, entende-se que a problemática ambiental no Oeste do Paraná deve ser vista como um tema transversal, quando associado à questão agrária. Deve-se destacar que a preocupação pela permanência e manutenção das unidades de conservação para a preservação ambiental 
TÉCNICAS AGRíCOLAS, PRESERVAÇÃO E IMPACTOS AMBIENTAIS NA REGIÃO OESTE DO PARANÁ

ocorre ao mesmo tempo em que, contraditoriamente, se estimula o desenvolvimento de práticas agrícolas danosas ao meio ambiente.

As políticas voltadas ao meio ambiente são definidas através de objetivos, sua compatibilização e integração, dando lugar à ação concretizadora, mediante um conjunto de programas, leis, regulamentos, projetos e decisões, bem como os métodos e ações para a solução de impactos gerados na natureza a partir de práticas agrícolas.

Os reflexos da modernização da agricultura no Oeste paranaense são representativos da realidade de outras partes do Estado e mesmo do País, em que as principais mudanças ocasionadas estão diretamente relacionadas à transformação na base técnica produtiva, nas relações de produção, na força de trabalho e na organização da estrutura fundiária, que por sua vez, acarretam consequências negativas ao meio ambiente.

Nesse processo, as desigualdades socioeconômicas entre os produtores se acentuaram, ou seja, as diferenças se intensificaram devido à introdução de técnicas produtivas externas no meio rural. A modernização é vista sob dois aspectos, o primeiro de caráter funcionalista que concebe a mudança do atrasado para o novo e, o segundo através de padrões de acumulação econômica, com crescente indução ao capital industrial adquirida. O contexto que encerra a valorização atual das causas ambientais é amplo e complexo, mas é possível destacar o aumento excessivo no nível de exploração dos elementos naturais, emergido a partir do século XIX e norteado por uma forma hegemônica de organização social que prioriza as necessidades e a lógica do capital.

Contudo, de fato a sustentabilidade das Unidades de Conservação depende mais da força dos atores sociais do que do planejamento técnico estatal. Nesse sentido, apesar da importância, necessidade, dimensão e complexidade do planejamento e da ação técnico científica, a resultante ambiental é constantemente fruto dos embates territoriais de uso e ocupação do espaço. 
TÉCNICAS AGRÍCOLAS, PRESERVAÇÃO E IMPACTOS AMBIENTAIS NA REGIÃO OESTE DO PARANÁ

\section{REFERÊNCIAS}

ANANIAS, A.C.CS.Um caminhar pela toponímia das microrregiões de Toledo e Foz do Iguaçu.Dissertação (Mestrado em Estudos da Linguagem), Londrina, 2013.

BARRETO, Alcyrus Vieira Pinto; HONORATO, Cezar de Freitas. Manual de sobrevivência na selva acadêmica. Rio de Janeiro: Objeto Direto, 1998.

BRITO, Maria C. W. De. Unidades de conservação: intenções e resultados. São Paulo: Annablume: FAPESP, 2003.

BRUM, Argemiro J. Modernização da Agricultura: trigo e soja. ljuí: Vozes, 1987.

COLODEL, José Augusto. Cinco séculos de História. In: SILVA, Gerson Henrique da; BUHÕES, Ronaldo; PERIS, Alfredo Fonseca (Org.). Messoregiões Oeste Paranense: diagnóstico e perspectivas. Cascavel: EDINUOESTE, 2002.

COSTA, C. C. de M.; REIS, P. R. da C.; FERREIA, M. A. M.; MOREIRA, N. C. Modernização agropecuária e desempenho relativo dos Estados brasileiros. Agroalimentaria, Mérida, v.18, n.34, p.43-56, 2012.

CUNHA, J. M. P. et. al. Diagnósticos regionais do Estado do Mato Grosso. Campinas: Núcleo de Estudos de População/UNICAMP, 2004. 225p. (Diagnósticos regionais do Estado do Mato Grosso, TEXTOS NEPO 49).

DEITOS, Nilceu Jacob. Presença da igreja no oeste do Paraná:a construção do imaginário católico (1930-1990). 2004. Tese (Doutorado em História)-Universidade Federal do Rio Grande do Sul, Porto Alegre.

DIAS, E. S. 2006. Desenvolvimento Regional e Conservação Ambiental: a "estrada do colono" como via de (des) integração do Oeste-Sudoeste Paranaense. UNESP. Presidente Prudente. Tese de Doutorado. 2006

GREGORY, Valdir. Os eurobrasileiros e o espaço colonial:migrações no Oeste do Paraná (1940/1970). Cascavel: EDUNIOESTE, 2002.

IPEADATA - Base de dados. <http://www.ipeadata.gov.br> Último acesso em 17 de dezembro de 2010. 
TÉCNICAS AGRÍCOLAS, PRESERVAÇÃO E IMPACTOS AMBIENTAIS NA REGIÃO OESTE DO PARANÁ

IPARDES - Instituto Paranaense de Desenvolvimento Econômico e Social. Leituras regionais: mesorregião geográfica Oeste Paranaense. Curitiba: IPARDES, 2006.

IPARDES - Instituto Paranaense de Desenvolvimento Econômico e Social. http://www.ipardes.gov.br. Ultimo acesso em 17 de julho de 2015.

LIMA, F.; ALVES, L. R.; PIFFER, M.; PIACENTI, C. A. O continuum setorial regional dos municípios da mesorregião Oeste paranaense. In: XLIII CONGRESSO DA SOBER: Instituições, Eficiência, Gestão e Contratos no Sistema Agroindustrial, 2005, Ribeirão Preto. Anais. Ribeirão Preto: SOBER, 2005.

PRADO JR., Caio. Formação do Brasil Contemporâneo - Colônia. 23.ed., 12ำimpressão, São Paulo: Editora Brasiliense, 2008.

PADIS, Pedro Calil. Formação de uma Economia Periférica: 0 caso do Paraná. São Paulo : Hucitec.1981.Co-edição Curitiba : Secretaria da Cultura e do Esporte do Governo do Estado do Paraná. Economia e planejamento : Série Teses e Pesquisas.

PIFFER, M. A teoria da base econômica e o desenvolvimento regional do Estado do Paraná no final do século XX. Tese (Doutorado em Desenvolvimento Regional) - Universidade de Santa Cruz do Sul, 2009.

RICARDO, Cassiano. Marcha para o Oeste. Rio de Janeiro: Editora da USP. Livraria José Olympio editora, vol. 2, 1970.

RIPPEL, R. Migração e desenvolvimento econômico no Oeste do Estado do Paraná: uma análise de 1950 a 2000. Tese (Doutorado em Demografia) Instituto de Filosofia e Ciências Humanas da UNICAMP - Universidade Estadual de Campinas, Campinas, 2005.

SISTEMA NACIONAL DE UNIDADES DE CONSERVAÇÃO DA NATUREZA SNUC - LEI № 9.985, DE 18 DE JULHO DE 2000. Disponível em: http://www. Ibama.gov.br/guiadechefe/java.htm. Acesso Setembro/2002.

SILVA, Francisco José Barretto da Silva. Conflitos de uso em Área de Proteção Ambiental: água, mineração e agricultura. Florianópolis, 2001. Tese (Doutorado Interdisciplinar em Ciências Humanas). UFSC, 2001.

TEIXEIRA, J. C. Modernização da agricultura no Brasil: impactos econômicos, sociais e ambientais. Revista Eletrônica da Associação dos Geógrafos Brasileiros, Três Lagoas, v.2, n.2, p.21-42, 2005. 
VEROCAI, I. A política e a gestão ambiental no Brasil.Rio de Janeiro, 1991. [Trabalho não publicado].

VINHAS, Moisés. Problemas agrário-camponeses do Brasil. Rio de Janeiro: Civilização Brasileira, 1992.

WEINER, J. Os Próximos cem anos. Rio de Janeiro: Editora Campus, 1992. 